\title{
ERRATUM
}

\section{Experimental Results on the Process of Goal Formation and Aspiration Adaptation}

\author{
Reinhard Selten \\ Department of Economics, \\ Institute for Empirical Research in Economics, \\ University of Bonn, Adenauerallee 24-42, 53113 Bonn, Germany \\ rselten@uni-bonn. de
}

B. Monien and U.-P. Schroeder (Eds.): SAGT 2008, LNCS 4997, p. 4, 2008.

(C) Springer-Verlag Berlin Heidelberg 2008

DOI 10.1007/978-3-540-79309-0_32

In the original version of the paper, two author details were incomplete. The correct author name and their affiliation is as follows:

\author{
Reinhard Selten, Sabine Pittnauer, and Martin Hohnisch \\ Department of Economics, \\ Laboratory for Experimental Economics, \\ University of Bonn, Adenauerallee 24-42, 53113 Bonn, Germany \\ rselten@uni-bonn. de
}

The original online version for this chapter can be found at http://dx.doi.org/10.1007/978-3-540-79309-0 2 